\title{
Cultivation of prospective plant seeds for Almaty city greening
}

\author{
A. Seilkhan ${ }^{1,2,}, S$. Dossymbetova ${ }^{3}, A$. Issabekova ${ }^{2}, A$. Kuspanova ${ }^{2}$, and \\ E. Kuandykova ${ }^{4}$ \\ ${ }^{1}$ Biomedical Research Centre, Al-Farabi Kazakh National University, 050040, 71 al- \\ Farabi Ave., Almaty, Kazakhstan \\ ${ }^{2}$ Abai Kazakh National Pedagogical University, 050010, 13 Dostyk Ave, Almaty, Kazakhstan \\ ${ }^{3}$ Almaty Technological University, 050012, Str. Tole Bi 100, Almaty, Kazakhstan \\ ${ }^{4}$ Kazakh National Agrarian University, Abai avenue 8, Almaty, 050010, Kazakhstan
}

\begin{abstract}
This Abstract. One of the most pressing problems of human society is the impersonality of urban spaces, of which green spaces are an integral part. Plants in an urbanized environment are not only a source of oxygen, noise and gas absorbers, etc., but also an element that unites and connects diverse residential buildings. This raises the question of the selfidentification of urban spaces. Problems include a meager assortment, the absence or presence in a single specimen of promising species that are not sufficiently stable in an urban environment. This article discusses the determination of seed productivity in laboratory conditions of plants Origanum vulgare collected from Ile Alatau of Kazakhstan and Berberis iliensis Popov collected from the Ile river of Almaty region. Laboratory experiments have shown high germination of Origanum vulgare and Berberis iliensis seeds, but the germination of seeds collected from different populations is different: for example, Origanum vulgare and Berberis iliensis plants had the highest laboratory germination of № 2 seeds. Origanum vulgare on the seventh day of growth reached $40 \%$ in population №1, 44\% in population №2 and $41 \%$ in population №3. Laboratory productivity for 25 days of growth was $91 \%$ in population №1, $95 \%$ in population №2, and $87 \%$ in population №3. The maximum validity of Berberis iliensis seeds in the second population is $92.5 \%$, and the lowest is $63 \%$ suitable for the first population.
\end{abstract}

\section{Introduction}

A modern green city is a dynamically developing and changing conglomeration, which has its own characteristics in all areas of development. Undoubtedly, the city's visiting card is its decoration through landscaping and landscaping.

Depending on the size of the city, the amount of funds allocated for gardening and the aesthetic taste of the gardeners, the appearance of the settlement is formed during the entire growing season [1]. When forming an assortment of promising plants for landscaping areas,

\footnotetext{
*Corresponding author: ainura_seilkhan@mail.ru
} 
attention should be paid to the selection of species and cultivars that combine unpretentiousness, stability and durability in culture with high decorative qualities that persist in the winter season. It is necessary to take into account the experience of introducing promising plants and, in general, the possibility of their cultivation and use in the conditions of the Almaty city. Many wild plants have sufficient reserves of raw materials in nature, but the rapid reduction of forest areas due to anthropogenic pressure and unplanned development and excessive use of cultivated plants contribute not only to a decrease in their number, but also to the extinction of a number of species in nature [2], as well as to a decrease in the number of species in biodiversity [3, 4], a decrease in natural populations [5], the extinction of endemic and rare species [6,7]. Therefore, an alternative way to obtain more raw materials is to grow medicinal plants in batanic gardens or agricultural fields [8]. Currently, many scientists are engaged in the cultivation of medicinal plants in various ways [9], for example, growing and storing them in the system of organic farming without the use of fertilizers and agricultural drugs. Or growing medicinal plants using new biogums used in agriculture [10, 11], biostimulators [12].

The city of Almaty, located in the southern part of the Republic of Kazakhstan, as well as other regional centers, is transforming year after year, changing and striving to improve its environment by all available means within the framework of the funds allocated for this.

Recently, the most common summer flower crops in the flower beds of the city of Almaty are petunia and tagetes, as well as coleus, cineraria and salvia in small quantities. Viols and tulips are included in the autumn planting. City flower beds are planted mostly one-component or two-component, and the contrast in them and the readability of the pattern is achieved mainly due to the variety of flower colors, therefore a large flower bed can be designed in such a way that only petunia or only viola in different colors, planted according to the drawing, will grow in it.

The first plant we wanted to grow Origanum vulgare, family of coarse flowers. In Kazakhstan, it grows throughout the southeastern part of the country and in the Ile Alatau, especially on rocky slopes, in sparse coniferous and birch forests, on the edges, among shrubs, in dry meadows.

Perennial, with a pleasant smell, rough pubescent plant with an oblique rhizome and erect tetrahedral, branched stems $30-70 \mathrm{~cm}$ tall. The leaves are petiolate, oblong-ovate, whole along the edge. The flower has a bell-shaped calyx, a two-lipped corolla $4-6 \mathrm{~mm}$ long; 4 stamens, of which 2 anterior ones protrude from the corolla, and 2 posterior ones are shorter than the corolla, and one pistil with a bifurcated stigma [13].

For medicinal purposes, the herb Origanum vulgare is harvested, the tops of the shoots are $20-30 \mathrm{~cm}$ tall, during the flowering of the plant. Dry by hanging them in a wellventilated place. After drying, thick stems are removed, and the greens themselves are slightly crushed. The raw material contains an essential oil, which includes thymol, carvacrol, sesquiterpenes, free alcohols, geranyl acetate. As an external remedy, preparations from the herb Origanum vulgare are used for abscesses, edema, boils, rashes, tonsillitis, stomatitis, gingivitis, migraine colpitis, hair loss, dandruff, eczema, scrofula (scrofula) and rickets in children [14].

Origanum vulgare grows best in warm, dry limestone soil, but otherwise it is quite undemanding. It is easy to plant with seeds that are sown in early spring in the nursery, you can also divide and transplant old bushes [15].

Berberis iliensis is a shrub 2-3 m tall, branched into strong coniferous branches. 5-6 thorns just whole. The annual twigs are wrapped in a variety of thorns with many branches. The surface of the leaves is soft, elongated or bloody, sharp. There are no deaf on the palm of the leaf. The length of the leaf blade is $1.5-4.5 \mathrm{~cm}$, the width is $0.6-30 \mathrm{~cm}$, the width of the stalk is $4-13-20 \mathrm{~mm}$ [16]. 
Distribution: the Jetysu Alatau and the Ketpen ridge, the southern part of the Dzungarian Alatau, on the banks of the Charyn and Shelek rivers, in the Ile-Balkhash region. It is also widespread in China along the Ile River [17].

\section{Materials and Methods}

The seeds of cultivated plants of origin must be harvested at the most favorable season or period of time to ensure the best quality of both the original seed and the finished product. It is well known that the quantitative concentration of biologically active components changes depending on the stage of plant growth and development. Seeds of Origanum vulgare were harvested 3 populations in September 2020 from the territory of Ile Alatau. 1 and № 2 populations of Origanum vulgare were found in the large Almaty gorge, while № 2 populations were located in the small Almaty gorge.

Seeds of Berberis iliensis M. Pop were harvested 3 populations in September 2020 in Almaty region. The first and second populations were found on the shore of the lower reaches of the Ile River, $3 \mathrm{~km}$ south of the village Bakanas (Balkhash district of Almaty region, South Balkhash coast). The third population was found on the right bank of the Charyn River

After cleaning and qualitative control of the collected plant seeds, we determined the productivity of seeds in the laboratory by using S.S. Lishchuk, M.G. Nikolaeva, M.N. Razumova, M.K .Firsov's methods [18-20].

\section{Results and discussion}

Laboratory yield is the percentage of selected seeds that have grown normally for 25 days under test conditions. On the first, third, and fourth days, the percentage of normal germination of the seed indicates the growth energy of the seed.

Based on the above methods, we monitored the laboratory performance of Origanum vulgare seeds for 25 days in a well-lit laboratory room at $+24^{\circ} \mathrm{C}$. The selection stage consisted of 100 seeds from each population, repeated four times. Seed growth of the studied species was observed from 2-3 days of growth. When determining the viability and laboratory productivity of seeds of Origanum vulgare, we obtained the following results.

Table 1. Germination of Origanum vulgare seeds during the study period \%

\begin{tabular}{|c|l|l|l|}
\hline Day/N & №1 & №2 & №3 \\
\hline 7 & $40 \%$ & $44 \%$ & $41 \%$ \\
\hline 25 & $91 \%$ & $95 \%$ & $87 \%$ \\
\hline
\end{tabular}

Note: $\mathrm{n}$ - is the number of plants in the group; ${ }^{*}-\mathrm{P}<0.05 ; * *$ - $\mathrm{P}<0.01 ; * * *$ - $\mathrm{P}<0,001$ - differential reliability of the control and experimental groups.

According to the Table 1 seeds of Origanum vulgare on the seventh day of growth reached $40 \%$ in population №1, 44\% in population №2 and $41 \%$ in population №3. Laboratory productivity for 25 days of growth was $91 \%$ in population №1, $95 \%$ in population №2, and 87\% in population №3. Consequently, the growth of Origanum vulgare seeds grown in a well-lit nutrient medium at a temperature of $+24^{\circ} \mathrm{C}$ was quite slow in three populations in the first 7 days, which means that Origanum vulgare sprouts grow very slowly in the first period of maturation and in the last days of germination, the seed germination frequency was noticeably higher in the period from 7 to 25 days.

High-quality seeds are determined by the "method of determining the quality of forest tree seeds" without being divided into fields. This method works as follows. This number of high-quality seeds is considered the color of the seed and seed contribution, with the 
characteristics of all grain seeds. First, the seeds are soaked in distilled water for 2-3 days, then they are cut on a sheet of white paper without taking them out and seen under a magnifying glass. And if there is any black color, it is a poor quality seed. After repeating this work 2-4 times in 100 copies from each population, we obtained the following information (Table 2).

Table 2. Seed quality of Berberis iliensis

\begin{tabular}{|c|c|c|c|c|c|c|}
\hline & \multicolumn{3}{|l|}{ №1 population } & \multicolumn{2}{c|}{ №2 population } & \multicolumn{2}{c|}{ №3 population } \\
\hline & \multicolumn{2}{|l|}{} & \multicolumn{2}{l|}{} \\
\hline $1^{\text {st }}$ time & 62 & 38 & 93 & 7 & 87 & 13 \\
\hline $2^{\text {nd }}$ time & 64 & 36 & 92 & 8 & 83 & 17 \\
\hline Average & 63 & 37 & 92,5 & 7,5 & 85 & 15 \\
\hline
\end{tabular}

Note: $\mathrm{n}$ - is the number of seeds in the group; * - $\mathrm{P}<0.05$; ** - $\mathrm{P}<0.01$; *** - $\mathrm{P}<0,001$ - differential reliability of the control and experimental groups.

From the above quantitative data we can see that the maximum validity of seeds in the second population is $92.5 \%$, and the lowest is $63 \%$ suitable for the first population. The main reason for the lowest in the first population is that the fruits and seeds are infested with various pests (microorganisms, fungi and various parasites).

Determination of laboratory performance; First, 200 seeds of morphological shape selected from each of the three studied populations of Berberis iliensis were analyzed, washed with a solution of $0.5 \%$ manganese (KMnO4) (slightly purple), then rinsed in petri dishes with manganese, and then the filter paper was symmetrical. We singed the number of the part 1,2,3,4. We divide each of them from 25 to 100 seeds so that they do not affect each other. Cover the lid with a little drop of manganese $0.5 \%(\mathrm{KMnO} 4)$ solution until it is completely moistened and write the number of the petri dish on the outside. We put it in front of a window where the warm sun shines well. Then we draw the following table, divide it into 25 days, check the performance every day and remember. And we pick the sprouts every day. Then we have the following information. Laboratory average seed yield ( 2 times in 100 pieces in each population in 25 days); It was $58.5 \%$ in 1 population, $96 \%$ in 2 populations, and $91.5 \%$ in 3 populations. In the first seven days of growing Berberis iliensis seeds in a Petri dish, the germination rate of population №2 and №3 were relatively high compared to population №1.

Laboratory experiments have shown high germination of Berberis iliensis and Origanum vulgare seeds, but the germination of seeds collected from different populations is different: for example, Origanum vulgare and Berberis iliensis plants had the highest laboratory germination of № 2 seeds. This is probably due to the remoteness of these populations from anthropogenic factors. This proves that a successful crop can be achieved by artificial cultivation of plant seeds of the species Berberis iliensis and Origanum vulgare, provided that favorable conditions are created.

\section{Conclusion}

To prepare a sufficient stock of cultivated plants in the greening sector, the properties of seeds and other reproductive organs must be accurately determined. It is necessary to collect all the necessary information about the quality and properties of seeds, and even the history of their growth, to determine the productivity of growing plant seeds in the laboratory. The environment has changed dramatically in recent years, especially in cities and towns. Man is in conflict with nature, and in order to solve the problem of life support, he needs to radically change the strategy and tactics of behaviour on our planet. 
In the summary, the search for new promising plants in the greening of modern megalopolises is one of the important trends of today, the Origanum vulgare is distinguished by its medicinal and aromatic properties, if we green the city with the help of this plant, the population will daily enjoy not only an aesthetic appearance, but also receive useful for body health.

The purpose of landscaping the city is the correct selection of plant species, both decorative and medicinal, because Berberis iliensis is rare, endemic. In addition, this plant has a special bright color that will harmoniously combine with other types of elements, which is very important in landscape design. Using such species in landscaping, we give a second wind to nature, protect rare plant species and contribute to the health of the city's population.

Thus, the greening of cities with promising plants contributes to an increase in the ecological culture of the population, awakening a sense of respect for nature and care for it.

\section{Acknowledgments}

Authors would like to thank the project "Creating a green university model in the context of sustainable development”, registration №0121 RKI0028

\section{References}

1. Steffen Lehmann S.A.P.I.EN.S, 3.2 (2010) URL: http://journals.openedition.org/sa piens/1057

2. A. Ydyrys, A. Serbayeva, S. Dossymbetova, A. Akhmetova, A. Zhuystay, E3S Web of Conferences, 222(2), 05021 (2020) DOI:10.1051/e3sconf/202022205021

3. A.S. Seilkhan, R. Mizadinov, I.R. Mizadinov, M.A. Kizdarbekova, Degradation of lands in central Asia, International Multidisciplinary Scientific GeoConference Surveying Geology and Mining Ecology Management, SGEM, (2016)

4. A.S. Seilkhan, R. Mirzadinov, A. Aksoy, A. Abulgaziyev, G. Kanat, Ecology, Environment and Conservation, 24(4), (2018)

5. A.S. Seilkhan, N.O. Kudrina, N.V. Cherepkova, Z.A. Inelova, S.M Shalgimbayeva, Pakistan Journal of Botany, 51(2), 649-655 (2019)

6. A.B. Akhmetova, N.M. Mukhitdinov, A. Ydyrys, A.A. Ametov, Z.A. Inelova, M. Öztürk, Journal of Animal and Plant Sciences, 28(5) 1400-1404 (2018)

7. Sh. Almerekova, Z. Mukhitdinova, N. Mukhitdinov, B. Tynybekov, A. Akhmetova, European Biotechnology Congress Journal of Biotechnology, 231S, 41 (2016)

8. E.A. Bukenova, Zh.M. Bassygarayev, A.B. Akhmetova, Zh.K. Zhunusbayeva, A. Ydyrys, Research on Crops 20(1), 210-214 (2019)

9. A. Seilkhan, S. Syraiyl, G. Turganova, E. Satbayeva, N. Erkenova, IOP Conference Series: Earth and Environmental Science, 699 (1), (2021)

10. A. Ydyrys, B. Yeszhanov, N. Baymurzaev, S. Sharakhmetov, A. Mautenbaev, B. Tynybekov, T. Baidaulet, E3S Web of Conferences, 169(2), 02012 (2020) DOI:10.1051/e3sconf/202016902012

11. A. Ydyrys, N. Abdolla, A. Seilkhan, M. Masimzhan, L. Karasholakova, E3S Web of Conferences, 222(1), 04003 (2020) DOI:10.1051/e3sconf/202022204003

12. A. Kakymova, Zh. Bassygaraev, E. Omargazi, Zh. Zhumabekova, A. Ydyrys, Biotechnology Congress Journal of Biotechnology, 233S, 41 (2017) 
13. Illustrated Guide to Plants of Kazakhstan, Nauka Publishing House of the Kazakh SSR, Alma-Ata, 2, 223 (1972)

14. A. Ydyrys, N. Zhaparkulova, A. Aralbaeva, A. Mamataeva, A. Seilkhan, S. Syraiyl, M. Murzakhmetova, Plants, 10(4), 666 (2021) https://doi.org/10.3390/plants10040666

15. V. Kumar, A. Dey, Encyclopedia of Food and Health (2016)

16. Illustrated Guide to Plants of Kazakhstan, Nauka Publishing House of the Kazakh SSR, Alma-Ata, 1, 399 (1972)

17. A. Begenov, N. Mukhitdinov, A. Ametov, S. Nazarbekova, A. Kuatbayev, B. Tynybekov, K. Abidkulova, A. Ydyrys, World Applied Sciences Journal, 30(1), 105109 (2014)

18. S.S. Lishchuk, Botan. zhurn. 76(11), 1623-1624 (1991)

19. M.G. Nikolaeva, M.V. Razumova, V.N. Gladkova, A handbook for germinating dormant seeds L Science, 347 (1985)

20. M.K. Firsova, 350 (M., Selkhozgiz, 1959) 